\title{
La bioética actual: las interrogantes de Heidegger
}

\author{
GUSTAVO FIGUEROA
}

Departamento de

Psiquiatría.

Escuela de Medicina

Universidad de Valparaíso.

Recibido el 22 de junio de

2011, aceptado el 19 de agosto de 2011 .

Correspondencia a: Gustavo Figueroa

Fono: (32) 2693671

(32) 2508550

E-mail: gfigueroacave@ gmail.com

\section{Bioethics today: Heidegger's questions}

Bioethics was born not only as an aftermath of medical technological advance but also from underlying philosophical conceptions about man, that determine scientific research. Analyzing occidental ethics, Heidegger showed that animalism was the only human dimension considered and thereby the domain of measurable objectiveness. He postulated that the essence of human existence as being-in-the-world is ethical and revealed through an original consciousness. Unlike moral conscience, original conscience calls to authenticity, to hear his constitutive nihilism as a "Beingrefered-to-death". The founding ground of bioethics may be to listen to this primary being-guilty prior to the derived guilts, e.g. faults, deficiencies and shortcomings of specific daily actions.

(Rev Med Chile 2011; 139: 1378-1383).

Key words: Bioethics; Conscience; Philosophy.

$\mathrm{E}$ 1 nacimiento de la bioética en los años setenta representó un giro pragmático y una doble interrogante teórica. Un giro porque trasformó radicalmente el quehacer clínico y científico de modo que hoy en día cualquiera acción al interior de la medicina debe ser sometida al análisis y aprobación bioéticas ${ }^{1,2}$. Una doble incógnita porque no se ha entendido con claridad los motivos que produjeron esta revolución en esos precisos instantes y no, por ejemplo, al finalizar la Segunda Guerra Mundial al conocerse las atrocidades médicas cometidas durante el conflicto $y$, especialmente, porque no se puede fundamentar con rigor las bases éticas que la sustentan ${ }^{3}$.

Nietzsche entregó una clave cuando afirma que "hasta ahora la moral nunca fue un problema... [], más bien fue, precisamente, aquello en donde luego de toda desconfianza, discordia, contradicción, se llegaba a un acuerdo entre todos, el sagrado lugar de la paz, donde los pensadores descansaban de sí mismos"4 Sagazmente continúa: "desde siempre, desde el tiempo en que se habla y se persuade en la tierra, la moral, precisamente, se ha manifestado como la mayor maestra de la seducción y, en cuanto a nosotros, filósofos, como la verdadera Circe de los filósofos" ${ }^{\text {. }}$. El problema vendría porque
"iLa Circe moral apenas ha soplado hacia ellos [los filósofos] y los ha hechizado! ¡todos estos hombres orgullosos y viajeros solitarios!3/4ahora ellos son, de repente, corderos, ahora quieren ser rebaño"6. Por ello planteamos la hipótesis de que la bioética podía constituir la Circe o encantadora de la medicina que ha impedido adentrarse en su génesis, principios y alcances que la sustentan ${ }^{7}$.

Martin Heidegger (1889-1976) renovó la metafísica occidental no sólo por las respuestas que entregó sino especialmente por la originalidad de las interrogantes que planteó. A partir de su obra "Ser y tiempo" (1927) la ética comenzó a concebirse de manera substancialmente distinta, o, al menos, impulsó a que se la comprendiera de forma diferente ${ }^{8}$. El presente estudio postula que sus contribuciones pueden ayudar a plantear interrogantes e iluminar dilemas de la bioética desde perspectivas inéditas y estimulantes.

El trabajo se dividirá en dos partes. En la primera, se formularán las graves dificultades que tienen las propuestas de Heidegger para poder ser aplicadas en ética. En la segunda, se examinarán tres de sus cuestionamientos básicos que pueden impulsar a la bioética a fundamentarse de manera distinta y proyectar opciones innovadoras. 


\section{Las objeciones de Heidegger}

Poco después de aparecido "Ser y tiempo" un discípulo le preguntó “¿Cuándo escribe usted una Ética?". Los motivos le parecían evidentes: la obra entregaba una riqueza impresionante de atisbos sobre la esencia del ser-humano o Dasein y la conciencia moral que por sí solos establecían las bases de una ética originaria e instaba a que el filósofo las desarrollara en la dirección propuesta o cuando menos insinuada.

La negativa de Heidegger fue rotunda porque se basaba en malentendidos. Su "Analítica Existencial" que des-cubre fenomenológicamente la estructura del sujeto como ser-en-el-mundo rompía con toda la tradición filosófica, pero no tenía nada que ver con una ciencia del hombre o iluminación del bien y fragilidad humanas porque no se ocupaba, metafísicamente hablando, del ámbito óntico sino del ontológico ${ }^{10-12}$. El primer malentendido radicaba en que las intenciones del filósofo estaban centradas en el "ser" mismo y no en el ser del "ente" llamado hombre, esto es, eran filosofía pura: la Analítica Existencial se movía en el plano ontológico, en cambio la Antropología, Psicología y Biología lo hacían en el nivel óntico. El estudio se había limitado al Dasein humano de manera preparatoria, preliminar, exclusivamente porque era un ente especialísimo pues su ser consiste en "ser-ontológico", "comprensor-de-ser" o "en-su- ser-le-va-su-ser"13. La segunda mala intelección apunta a que la Biología, Psicología y Antropología investigan aspectos concretos, empíricos y positivos sobre la persona y por ello sus conocimientos son indispensables. Pero no se han preguntado por la forma de ser -específica, esencial, distintiva- del individuo. Peor, dan por supuesta su manera de ser o ésta viene configurada antes de comenzar sus investigaciones: todas son aquellas interpretaciones "del hombre que, en el fondo, ya sabe[n] qué es el hombre y por eso no pueden [n] preguntar nunca quién es" ${ }^{\prime 14}$. La última insuficiencia peca por la tendencia solapada de la Antropología, Psicología y Biología a privilegiar al hombre de manera tal que desembocan en un antropomorfismo, esto es, situarlo en un puesto especial en el cosmos, de modo que la realidad culmina en su ser y así se constituye en medida absoluta y a continuación evalúa a todas las demás criaturas con respecto a él ${ }^{15,16}$.

Durante años estas objeciones mayúsculas inhibieron su aplicación en la ética médica. Si la bioética pretende utilizar creativamente los aportes de Heidegger previamente necesita resolver ¿es posible transitar desde la Analítica Existencial -ontología- a la bioética-nivel óntico? Cuatro indicaciones suyas ayudan. Primero, aunque la Analítica Existencial no pretende ser una antropología, ésta necesita una fundamentación filosófica estricta, y él admite que sus análisis particulares de las estructuras básicas de existencialidad, facticidad y caída han proporcionado "algunos «fragmentos», y no inesenciales" en esa dirección, constituyéndose en fundamentos específicos a desarrollar concretamente en un futuro ${ }^{17-21}$. Segundo, en los seminarios a médicos, psiquiatras y psicólogos que condujo con Medard Boss puso en práctica sus puntos de vista en los casos clínicos que le presentaban, tanto para sentar las bases de una medicina propiamente humana como para que ésta prestara ayuda a los sujetos existencialmente sufrientes ${ }^{22}$. Los dos últimos puntos son especialmente importantes para nuestro tema porque se refieren a la conciencia moral y al plano óntico. Tercero, su Analítica está orientada por "un ideal fáctico" de existencia, pero esta pre-comprensión ha de ser confirmada concretamnete por el "factum" existencial de la conciencia. Cuarto, al analizar la resoluciónanticipativa (Entschlossenheit), que permite al individuo obtener su más alto grado de ser-símismo-auténtico en el ser-referido-a-la-muerte, indica que, para alcanzar esa posibilidad, requiere una atestiguación óntica (existentielle Bezeugung), y esta se logra por medio de la conciencia moral, conciencia que no es suficientemente original en la vida cotidiana por lo que precisa ser interpretada hermenéuticamente.

\section{Modo de ser: el hombre neuronal}

Las ciencias neurocognitivas actuales han revolucionado tan profundamente la imagen del ser humano que se lo caracteriza alternativamente como "hombre neuronal", "cerebro que piensa", "mente computacional" o "cerebro ético"23-27. Ahora bien, estas definiciones no sólo son producto del avance tecnológico sino obedecen a una concepción del hombre que explícitamente se funda en una dimensión circunscrita, la dimensión de la animalidad, biología y finalmente naturaleza física. Esta concepción está sustentada 
en tres pre-supuestos: la ciencia moderna como determinante de la verdad, el pensar calculador y la realidad como presencia.

Primero: la medicina es ciencia moderna en un doble sentido; por una parte, dictamina lo que las cosas son y, como afirma Husserl, "no admite ninguna autoridad a su lado y por encima suyo", y por otro, no se interesa por la interna necesidad del enfermo ${ }^{28}$ ¿Qué quiere decir? No se cuestiona por la verdad del enfermo -explicarlo desde sí mismo- sino sustituirlo por algo más preciso, la precisión objetiva. Lo que sucede es que su esencia radica en la investigación (Forschung), vale decir, en la circunscripción por anticipado a "un" campo delimitado y exactamente caracterizado de conocimiento; como esquema o proyecto-previo (Vorentwurf) pre-determina el saber, aprehende y encuentra como objeto posible solamente lo que "su" tipo de representación ha admitido con anterioridad ${ }^{29}$. Segundo: si antes que acatar serena y respetuosamente (Gelassenheit) la esencia del enfermo es el médico el que implanta el métron o la medida para mensurar y computar todo lo que puede tenerse por cierto, es gracias a un tipo de pensar, el calculador o representativo (Verrechnen), pensar que da prioridad a la actitud objetivadora, operacional, dominadora, instrumental, clasificatoria, con tendencia a priorizar el control del investigador y el poder de su hacer sobre lo investigado $^{30}$. Tercero: la consecuencia es que el hombre -sano y enfermo-vale decir, "la realidad" (Wirklichkeit) proviene del producir o actuar (wirken), de un "proceder ejecutivo-asegurador". Lo real y actual es lo que hace acto de presencia, lo hechopresente (An-wesen) es un resultado (Er-gebnis), una secuela, una consecuencia, un efecto (Er-folg) instaurado por el actuar del médico investigador ${ }^{31}$.

Ahora resulta claro que la dimensión escogida para definir al hombre es producto (das Herausgestellte) del im-poner del investigador y Heidegger demuestra que esta caracterización obedece a una historia. Aristóteles sentó las bases al determinarlo como zóon lógon ékhôn, animal dotado de razón y esta "animalidad" ha imperado sin contrapeso sobre la humanitas hasta la época actual. Como ejemplo, Searle asevera que "los fenómenos mentales [léase humanos] están causados por procesos neuropsicológicos del cerebro y son a su vez rasgos del cerebro.... [En este] «naturalismo biológico», los eventos y procesos mentales son parte de nuestra historia natural biológica en la misma medida en que lo son la digestión, la mitosis, la meiosis o la secreción de enzimas" 32 .

Heidegger cuestiona este materialismo porque perpetúa el pensarlo como substantia que es la versión romana de la ousía helena, que dio un paso decisivo pero irreversible hacia su "entificación" sin interrogarse por su esencia, "no es considerar a su altura la esencia del hombre, ni pensarla en su procedencia". Esto es, "la Metafísica [de la ciencia] piensa al hombre desde la animalitas y no lo piensa hacia su humanitas"; que "se pueda investigar al ser humano en su calidad de organismo, desde la perspectiva de las ciencias naturales, no prueba en modo alguno que en eso «orgánico», en el cuerpo científicamente explicado, resida la esencia del hombre", aún "podría ser que la naturaleza ocultase su esencia en la cara que presenta al dominio técnico". Para Heidegger las consecuencias son inevitables: "al llamar «hombre» al existente que se va a interrogar se le pone ya de antemano dentro de una determinada concepción categorial", por lo que es necesario atreverse "a una resistencia abierta contra el «humanismo» del homo humanus y su fundamentación"”.

\section{La existencia ética}

Si es im-propio hablar de "hombre" por presupuestos metafísicos insuficientes, más aún es designarlo "cerebro que piensa", -como Changeaux cuando caracteriza lo moral: "la ética normativa es sencillamente una adaptación dispuesta por la selección natural para hacer de nosotros seres sociales". Entonces Heidegger lo denomina " $D a$ sein" o "Existencia" porque ésta define su esencia: "comprensor-de-su-ser"33,34.

La ciencia natural que pro-pone la hipótesis de la moral como adaptación es rechazada por Heidegger porque la norma ética (Gesetz) no es un ob-jeto-puesto (ge-setzt) por un sub-jeto abstracto (selección natural) para adaptarse. Esta ciencia trabaja suscribiendo tres supuestos metafísicos. Primero: la escisión sujeto-objeto, que es obra del científico; lo investigado es una re-presentación (Vor-stellung) del investigador, en que simultáneamente son dados sujeto y objeto, sujeto como representante y objeto como representado. Segundo: La certeza de lo aseverado resulta provenir del investigador que re-presenta, porque representar es poner el "sujeto" al "objeto" desde sí mismo 
y así asegurarse por medio del provocar, medir, constreñir y coaccionar. Tercero: ni la objetivación del mundo moral ni la subjetivización del científico son lo que se muestra, sino lo puestodelante (Gegen-stand), en-frente, es lo ob-jetivo (lo que se lanza) para dominar y someter, en este sentido, intervenir para unificar el conocimiento y conseguir un mundo coincidente con el del hombre de ciencia.

Heidegger pone en guardia porque enfatiza que la objetividad no pasa de ser "una" de las maneras posibles de hacerse presente la Realidad, pero no la incondicional y, sobre todo, no la fundamental sino marginal y, si nos atenemos a ella exclusivamente, desfiguradora de lo que aparece, aún aniquiladora (Vernichtung) especialmente cuando capta algo tan sutil como la eticidad del ser humano

Pero tampoco se trata de un "sujeto" moral porque nuestra existencia "es" ética y nace del factum que somos ser-en-el-mundo. A diferencia de la científica, la descripción fenomenológica no impone sino des-cubre y deja-ser (sein-lassen) a nuestra unidad en sus tres componentes: existencia, facticidad y caida. "Existencia” señala que somos siempre-proyecto-de-nuestro-ser, "facticidad" que estamos-arrojados-ya en un mundo que nos precede-y-estamos-implantados y "caida" (Verfallenheit) que nos entendemos primariamente desde aquello-que-nos-ocupa diariamente. O sea, 1) libres para autoelegirnos (Selbstwahl); 2) no-libres radicalmente porque nunca fuimos nuestro propio fundamento, menos dueños incondicionados del propio ser; y 3 ) esta carencia-de-ser, negatividad, ausencia de autonomía la encubrimos seduciéndonos con las cosas que manejamos, fascinándonos con las novedades del mundo social y parloteando lo de toda-la-gente o impersonal "se" ("se" dice, "se" afirma).

Esta deficiencia esencial, manquedad ontológica o no-ser primordial hace necesario diferenciar entre una falta cometida en la vida y una falta en el fundamento de nuestro ser. Mientras la primera se repara saldando el defecto en que se incurrió mediante una acción, la segunda caracteriza nuestra propia condición. Frente al sentido-de-su-hacer destaca el sentido-de-su-ser, frente al estar-endeuda se alza el ser-deudor. Ahora queda claro la sustancia ética inmanente a la existencia. La "mala conciencia” crítica y censora es una conciencia "a medio camino" porque cuestiona la falta concreta para no mirar al fondo de sí-mismo, su fundamento que es nuestra inherente negatividad.

Así Heidegger distingue dos modos de conciencia (Gewissen): la derivada o moral y la existencial $\mathrm{u}$ originaria, la que surge a partir de hechos concretos y la constitutiva de nuestro ser. Las dos se expresan en una llamada $(R u f)$, pero esta llamada incumbe a asuntos radicalmente diferentes.

\section{Conciencia moral y conciencia originaria}

Lo dicho hasta aquí apunta a la coexistencia de dos modalidades de existencia aunque de alcance divergente: impropia y propia. La Existencia im-propia o "caida" es aquella en que inmediata, regular y cotidianamente estamos inmersos (los instrumentos que utilizamos, las tareas en que nos afanamos) y poseidos por lo vigente públicamente, el "se" ordinario (las habladurías, la avidez de novedades, la dictadura del impersonal "uno"). Este espacio envolvente e in-auténtico de significación -de todos y de nadie- es una vorágine y torbellino en que se está apresado y en el que no se repara en sí-mismo, por lo que "uno-mismo" se entiende a sí como cosa ("cerebro-que-piensa”). Cosa entre cosas, ciega para sí misma, interesada en su cosificación y empeñada en desconocerse, esta alienación vital (Entfremdung) no es transitoria sino constitutiva y se lleva a cabo como apaciguadono-ser-propietario-del-más-peculiar-ser.

Contrariamente, la Existencia propia o auténtica (Eigentlichkeit) atiende a su más propia posibilidad que se es y tal como se es y así se hace responsable de su ser. ¿Algo la impide y por ello la rehuye? La desazonante in-hospitalidad (Unheimlichkeit) o no-estar-en-casa (Unzuhause) que constituye su esencia, su inquietante y ominosa nihilidad de nunca-poder-ser-su-propio-fundamento. ¿Cómo arriesga enfrentársela? Por la conciencia originaria -querer-tener-conciencia (Gewissen-habenwollen) o "disposición-a-la-angustia"-, que llama a experimentar y asumir sin vacilación la finitud inmanente al ser-en-el-mundo.

¿Cómo llaman? Creyéndose autosuficiente, la conciencia moral se auto-determina (Selbsbestimmung) como "sujeto" auto-desdoblándose en una voz objetivante que se hace-presente-a-símisma (Anwesen) como "tribunal" que compara críticamente su conducta con una medida objetiva ideal que posee fuerza vinculante porque ésta está 
auto-establecida (sich-selbst-setzen), producto de la inflación de esta subjetividad legisladora "en la dimensión del «calcular» según el «debe» y el «haber»".

¿Y la culpa originaria? Sin escindirse entre sujeto-objeto, sin "auto-determinarse" sino "autoelegirse", la voz llama a "si-mismo" a rehusar ensalzarse como altanero uno-mismo-como-todos, a "nadie" distinto de sí-mismo, a "nada" sobre lo que quepa parlotear o regatear, a "callar" al volverse a sí y escuchar la "silenciosidad-de-sí-mismo". Como experiencia radical la conciencia-originaria ni juzga ni condena, sólo encara con su primario ser-deudor: estar-en-deuda y no-ser-el-fundamento-de-nuestro-ser. Su voz insonora (si-mismo, nadie, nada, callar, silencio) entrega un testimonio irrefutable de su más auténtica posibilidad: serpara-la-muerte (Sein-zum-Tode). Esta posibilidad es la resolución-anticipadora (Entschlossenheit), desenlace existencial de haber entendido la voz de la conciencia que ahora asume su revelación: se rescata de su estar-absorbido-por-el-mundo hacia un afrontar sin máscaras su "facticidad": ser-sí-mismo-en-cuanto-referido-a-la-muerte ${ }^{35-38}$.

\section{Incitaciones}

Heidegger no da respuestas sino incitaciones a la bioética para que se plantee desde fundamentos distintos.

1) Las imágenes del hombre que sustentan a la bioética no proceden exclusivamente del avance científico sino expresan concepciones metafísica e históricamente implícitas (materialismo biologicista).

2) La ética es un constitutivo del ser humano. Ethos designa primariamente el habitar o familiaridad originarios del hombre como ser-en-elmundo, confiarse a esta morada que, aunque le señala su finitud desazonadora, le permite abrir sus posibilidades de ser sí-mismo.

3) Empero la Existencia no viene dada hecha sino tiene-que-realizarse $(Z u$-sein), auto-elegirse o erigir su propio ser; a diferencia del animal, no está "ajustado" a su ambiente sino "tiene que hacer su propio ajustamiento", esto es, "justificar-se"39.

4) Contrariamente la bioética es derivada de la ética moderna, nació de una subjetividad autolegisladora que hizo de la voluntad incondicionada fundamento de las normas e ideales.
5) Los valores bioéticos valen porque son puntos de vista directivos para un actuar calculador, son funciones de una subjetividad soberana que ve en tanto que "ha propuesto lo visto en cuanto tal y así lo ha puesto". Los valores son "obligatorios" porque son lo puesto por la voluntad, y de-puesto y re-puesto por ella según su arbitrio.

6) Heidegger está contra esta violencia legitimadora unilateral, y no la bioética. La fuerza vinculativa como mera objetividad necesita ser sustituida por un tipo de valorar que deje ser a las personas tal como son o valerse por sí-mismas, en la integridad de su ser. En lugar de postular una autonomía irrestricta (Kant) o una voluntad con pretensiones totalizadoras y soberanas (Nietzsche) o un deber-ser absoluto que ordena el mundo humano (Hegel), disfrazadas en consensos de "todos los involucrados", se requiere aceptar la finitud constitutiva que hace que toda elección del enfermo sea indigente, constreñida por la actual época histórica, pero que considere a esta época en todas sus dimensiones.

7) Aprender a sufrir (morir), a existir abierto al misterio que nunca está a su disposición y que lo interpela a escuchar su propia esencia, sin ser arrebatado por ningún calcular ni medir; cuidadoso respetar que, una vez asumido, posibilitará el compromiso concreto cotidiano ya no más absorvido por un despeñadero de metas y fines inmediatos. Este fundamento originario permitirá los otros niveles de la bioética: prudencial ( $p h r o ́-$ nesis) o confianza y deontológico o del respeto ${ }^{40}$.

\section{Referencias}

1. Gracia D. Fundamentos de bioética. Madrid: Eudema, 1989.

2. Figueroa G. [Professional responsability: maximal, minimal, excellence and veracity]. Rev Med Chile 2006; 134: 233-9.

3. Figueroa G. [Why bioethics today?] Rev Med Chile 1995; 123: 777-84.

4. Nietzsche F. Die fröhliche Wissenschaft. Werke in drei Bänden II. München: Hanser, 1966. p. 7-274.

5. Nietzsche F. Morgenröte. Gedanken über die moralischen Vorurteile. Werke in drei Bänden I. München: Hanser, 1966. p. 1009-279.

6. Nietzsche F. Aus dem Nachlass der Achtzigerjahre. Werke in drei Bänden III. München: Hanser, 1966. p. 415-925.

7. Figueroa G. [Is bioethics Circe, the enchantress of medicine?] Rev Med Chile 2001; 129: 209-17. 
8. Heidegger M. Sein und Zeit. 10. Aufl. Tübingen: Niemeyer, 1963.

9. Heidegger M. Brief über den "Humanismus". Gesamtausgabe 9. Frankfurt: Klostermann, 1976. p. 313-64.

10. Beaufret J. Introduction aux philosophies de l'existence. De Kierkegaard à Heidegger. Paris: Denoel/Gonthier, 1971.

11. Gadamer H-G. Existentialismus und Existenzphilosophies. En: Heideggers Wege. Gesammente Werke. Band 3. Tübingen: JCB Mohr (Paul Siebeck), 1987. p. 7-17.

12. Heidegger M. Einführung in die Metaphysik. Gesamtausgabe 40. Frankfurt: Klostermann, 1983.

13. Heidegger M. Ontologie. (Hermeneutik der Faktizität) (1923). Gesamtausgabe 63. Frankfurt: Klostermann, 1982.

14. Heidegger M. Die Zeit des Weltbildes. En: Holzwege (1935-1946). Gesamtausgabe 5. Frankfurt: Klostermann, 1984. p. 69-104.

15. Heidegger M. Kant und das Problem der Metaphysik (1929). Gesamtausgabe 3. Frankfurt: Klostermann, 2010.

16. Scheler M. Die Stellung des Menschen in Kosmos. Gesammelte Werke. Band 5. Bern: Francke, 1956.

17. Figueroa G. Hacia una antropología psiquiátrica II. Los fundamentos filosóficos. Rev Chil Neuro-Psiquiat 1996; 34: 381-90.

18. Fahrenbach H. Heidegger und das Problem einer "philosophischen” Anthropologie. En: Klostermann V, Hrsg. Durchblicke. Martin Heidegger zum 80. Geburtstag. Frankfurt: Klostermann, 1970. p. 97-131.

19 Ignatow A. Heidegger und die philosophische Anthropologie. Messeheim: Athenaum-Hain, 1979.

20. Figueroa G. Los fundamentos del análisis existencial. Rev Chil Neuro-Psiquiat 1995; 33: 21-9.

21. Heidegger M. Die Grundbegriffe der Methphysik. WeltEndlichkeit-Eisamkeit (1929/1930). Gesamtausgabe 29/30. Frankfurt: Klostermann, 1983.

22. Heidegger M. Zollikoner Seminare. Protokolle-Zwiegespräche-Briefe. 2. Auflage Frankfurt: Klostermann, 1994.
23. Changeaux J-P. L'homme neuronal. Paris: Fayard, 1983.

24. Gazzaniga MS. The ethical brain. New York: Dana Press, 2005.

25. Moll J, de Oliveira-Souza R. Moral jugdments, emotions and the utilitarian brain. Trnds Cogn Sci 2007; 11: 31921.

26. de Vignemont F, Singer T. The empathic brain: how, when and why? Trends Cogn Sci 2006; 10: 435-41.

27. Jackendoff R. Consciousness and computational mind. Cambridge: MIT Press, 1990.

28. Husserl E. Die Philosophie als strenge Wissenschaft. Frankfurt: Klostermann, 1981.

29. Heidegger M. Wissenschaft und Besinnung. En: Vortäge und Aufsätze. 5.Aufl. Pfullingen: Neske, 1967. p. 41-66.

30. Heidegger M. Gelassenheit. Pfullingen: Neske, 1959.

31. Heidegger M. Das Ding. En: Vorträge und Aufsätze. 5. Aufl. Pfullingen: Neske, 1967. p. 157-75.

32. Searle JR. The rediscovery of the mind. Cambridge: The MIT Press, 1992.

33. Changeaux J-P, Ricoeur P. Ce qui nous fait penser. La nature et la régle. Paris: Odile Jacob, 1998.

34. Biemel W. Heideggers Begriff des Daseins. Studia Catholica 1949; 24: 113-29.

35. Cerezo P. De la existencia ética a la ética originaria. En: Cerezo P, Duque F, Leyte A, Martínez Marzoa F, Peñalver P y Rodríguez R. Heidegger: la voz de tiempos sombríos. Barcelona: Ediciones del Serbal, 1991. p. 11-79.

36. Rodríguez R. Hermenéutica y subjetividad. 2. edición. Madrid: Trotta, 2010.

37. Barroso Fernández O. Destino y responsabilidad. El lugar de la ética en la filosofía de Zubiri y Heidegger. En: Nicolás JA, Espinoza R, editores. Zubiri ante Heidegger. Barcelona: Herder, 2008. p. 335-84.

38. Figueroa G. [Bioethics of Sigmund Freud's death. Euthanasia or appopriation?] Rev Med Chile 2011; 139: 511-6.

39. Zubiri X. Sobre el hombre. Madrid: Alianza, 1986.

40. Ricoeur P. Les trois niveaux du jugement médical. Esprit 1996; 12: 21-33. 